\title{
EDUCAÇÃO ANTIRRACISTA E A LEI 10.639/03: UMA PROPOSTA DE IMPLEMENTAÇÃO A PARTIR DO NOVEMBRO NEGRO DO IFBA
}

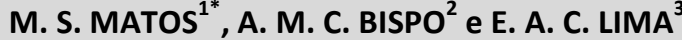 \\ ${ }^{1}$ Universidade Federal de Minas Gerais - UFMG \\ ${ }^{2-3}$ Instituto Federal de Educação, Ciência e Tecnologia da Bahia - IFBA \\ mauriciosousamatos@gmail.com
}

Submetido 21/07/2016 - Aceito 24/07/2017

DOI: $10.15628 /$ holos. 2017.4861

\section{RESUMO}

O projeto Novembro Negro do Instituto Federal de Educação, Ciência e Tecnologia da Bahia (IFBA) campus Vitória da Conquista, objetiva contribuir para o cumprimento da lei no 10.639/03 que torna obrigatório nas escolas da educação básica do Brasil o ensino da História e Cultura Afro-Brasileira e Africana. Com base na lei, a Coordenação do referido projeto, desde 2011, promove uma série de atividades, como pesquisas etnográficas das comunidades negras da região, produção de documentários sobre Comunidades
Quilombolas, mostras fotográficas, pesquisas dentre os estudantes do campus com o percentual de alunos que declaram a cor negra, que são favoráveis às ações afirmativas (cotas), e quanto à percepção do racismo no IFBA, sobretudo estabelecendo uma pedagogia antirracista que valorize e preserve a histórica herança da cultura afro-brasileira, demonstrando possibilidades em se incorporar a proposta da lei no cotidiano dos institutos federais.

PALAVRAS-CHAVE: Consciência Negra, Lei 10.639/03, IFBA, Ações Afirmativas, Vitória da Conquista.

\section{BLACK NOVEMBER IN THE IFBA: A PROPOSAL OF REFLECTION ON THE IMPLEMENTATION OF THE LAW 10.639/03}

\begin{abstract}
The Black November in the Federal Institute of Education, Science and Technology of Bahia (IFBA), Vitória da Conquista Campus, objectives to enforce the law no 10.639/03 mandating basic education schools in Brazil to teach Brazilian African History and Culture. Based on this law, the coordination of this project since 2011 promotes a series of activities, such as ethnographic studies of black communities in the region, producing documentaries on Quilombo Communities,
\end{abstract}

photographic exhibitions, research among students on campus with the amount of students who declare to be black, and which favor affirmative action (quotas), and how the perception of racism in the IFBA, especially in establishing an antiracist pedagogy that values and preserves the historical heritage of African-Brazilian culture, demonstrating possibilities in incorporating the proposal of the law in the daily life of the federal institutes.

KEYWORDS: Black Consciousness, Law 10.639/03, IFBA, Affirmative Action, Vitória da Conquista. 


\section{INTRODUÇÃO}

Em face das demandas da educação e dos diversos contextos da diversidade humana, em que se inserem educadores e educandos, o Instituto Federal de Educação, Ciência e Tecnologia da Bahia [IFBA] campus Vitória da Conquista, sob a coordenação dos professores da área das ciências humanas, com o auxílio de estudantes bolsistas e em parceria com a Universidade Estadual do Sudoeste da Bahia, realiza desde 2011 o projeto "Novembro Negro", o qual se fundamenta na Lei n. 10.639 (2003), que torna obrigatório o ensino da História e Cultura Afro-brasileiras e Africanas nas instituições de ensino público e privado no Brasil. A discussão das realidades nas quais o negro é historicamente inserido, ou mesmo excluído, demonstra a relevância de tal discussão e expande as possibilidades de se entender o mundo e a (des)humanidade.

O contexto histórico, político, social e educacional que justifica a necessidade da sanção da Lei no 10.639 em 2003 emblema as implicações de um processo escravocrata com sérias sequelas sociais, a inexistência de um regime democrático até poucas décadas atrás, a institucionalização da criminalização e exclusão dos negros e pobres, entre outras, contribuindo para o reconhecimento e visibilidade do racismo e do mito da democracia racial. Visto esse contexto e suas implicações, destacam-se na luta dos movimentos sociais o Movimento Negro, em especial corroborado pela Marcha Zumbi dos Palmares em 1995; os dados sociodemográficos demonstrando a condição de desigualdade racial, produzidos pelo IPEA em 2001; a participação do Brasil na 3a Conferência Mundial de Combate ao Racismo, Discriminação Racial, Xenofobia e Intolerância Correlata de Durban em 2001; a criação da Secretaria Especial de Promoção de Políticas de Igualdade Racial (SEPPIR) em 2003 e da Secretaria de Educação Continuada, Alfabetização e Diversidade (SECAD) no âmbito do Ministério da Educação em 2004; a sanção da Lei de Cotas nas universidades e institutos federais em 2012 e da Lei de Cotas no serviço público federal em 2014.

As próprias limitações quanto aos estudos e pesquisas sobre a institucionalização da Lei $n$. 10.639/03 na Rede Federal de Educação Profissional e Tecnológica evidenciam a necessidade em se consolidar e divulgar experiências de êxito que contribuam para inserção dessa importante temática no currículo e na prática de aprendizagem cotidiana dessas instituições educacionais.

Conforme aponta Rocha (2015) em pesquisa que verifica experiências positivas em algumas instituições da Rede Federal de Educação Profissional e Tecnológica, ao mesmo tempo que em algumas instituições sinaliza em seus resultados uma baixa institucionalização da referida lei no contexto de toda a rede composta por 41 instituições (os 38 Institutos Federais, os dois Cefets e a UTFPR).

[...] a Lei no. 10.639/2003 ainda se encontra em um processo gradual de implantação na Rede Federal de Educação Profissional, bem como a temática da referida lei apresenta-se com baixa institucionalização, a partir da grande maioria dos PDIs dessas instituições (Rocha, 2015, p. 105).

Diante desse cenário, a elaboração do Plano Nacional que estabelece metas e estratégias de Implementação das Diretrizes Curriculares Nacionais para a Educação das Relações ÉtnicoRaciais e para o ensino de História e Cultura Afro-Brasileira e Africana (2004) , desenvolvido no sentido de compor um marco histórico. A Lei n. 10.639/2003 simboliza, simultaneamente, um ponto de chegada das lutas antirracistas no Brasil e um ponto de partida para a renovação da qualidade social da educação brasileira. Conforme sinaliza Ferraz (2011, p. 20) 
A Lei n. 10639/2003 pode ser considerada um ponto de chegada de uma luta histórica da população negra para se ver retratada com o mesmo valor dos outros povos que para aqui vieram, e um ponto de partida para uma mudança social. Na política educacional, a implementação da Lei n. 10.639/2003 significa ruptura profunda com um tipo de postura pedagógica que não reconhece as diferenças resultantes do nosso processo de formação nacional (Ferraz, 2011, p. 20).

Colocando-se sobre o crivo da articulação, o objetivo geral da proposta consiste na promoção da temática afro-brasileira e africana nas disciplinas do currículo do IFBA, buscando, sobretudo, flexibilizar o "currículo da escola técnica". Como resultado, a culminância do projeto conta com a apresentação da pesquisa "Demandas de Cidadania" quanto à percepção do racismo no IFBA, realizada com o percentual de alunos que declaram a cor negra e que são favoráveis às ações afirmativas (cotas). Realizam-se ainda a exposição de material audiovisual produzido pelos estudantes do campus, palestras e debates com pesquisadores da temática, apreciação de comidas afro-brasileiras, apresentações culturais (capoeira, samba de roda e maculelê), pesquisas etnográficas das comunidades negras da região, produção de documentários sobre Comunidades Quilombolas e mostras fotográficas.

O fomento à discussão acerca do processo histórico-social em que se insere o ser humano enquanto indivíduo, sujeito da/na sociedade torna-se necessário e essencial à construção de uma consciência e identidade que resgate toda a pluralidade étnica, cultural, religiosa e linguística para que se extingam as desigualdades, principalmente sociais e raciais. Nesse contexto

[...] a Lei $n^{\circ} 10.639 / 03$ pode ser interpretada como medida de ação afirmativa, uma vez que tem como objetivo afirmar o direito a diversidade étnicorracial na educação escolar, romper com o silenciamento sobre a realidade africana e afro-brasileira nos currículos e práticas escolares e afirmar a história, a memória e a identidade de crianças, adolescentes, jovens e adultos negros na educação básica e de seus familiares (Gomes, 2010, p. 20).

Significando deste modo o reconhecimento da importância do combate ao preconceito, ao racismo e à discriminação na redução das desigualdades historicamente imputadas à população negra. Pois como lembra Macedo (2014, p. 18) "este assunto deve permear a ação gestora e também docente, de forma a ser refletida e debatida em todos os momentos educacionais da instituição" de modo a sensibilizar a instituição escolar como um todo.

São inegáveis os avanços que a educação brasileira vem conquistando nas décadas mais recentes. Considerando as dimensões do acesso, da qualidade e da equidade, no entanto, pode-se verificar que as conquistas ainda estão restritas ao primeiro aspecto e que as dimensões de qualidade e equidade constituem os maiores desafios a serem enfrentados neste início do século XXI (BRASIL, 2004).A fim de comemorar o mês da Consciência Negra, que culmina no Dia Nacional de Zumbi e da Consciência Negra - 20 de novembro -, foi realizado em 2011 no IFBA campus Vitória da Conquista o projeto Novembro Negro, conforme ilustra a marca oficial nas Figuras 1 e 2, cujo tema foi "Consciência Negra: Implementando a lei 10.639/03", enquanto o tema em 2012 foi "Uma Conquista de Quilombos: História do negro em Vitória da Conquista" e, em 2013, "Conquista e a construção de sua identidade afro-indígena: negros e indígenas - uma unidade indissociável, uma dor, uma resistência, uma sabedoria, nossa origem!", edição essa que se orientou pela Lei n. 11.645 (2008), a qual torna obrigatório o ensino da História e Cultura Afro-brasileira, Africana e Indígena nas instituições de ensino público e privado no Brasil. 


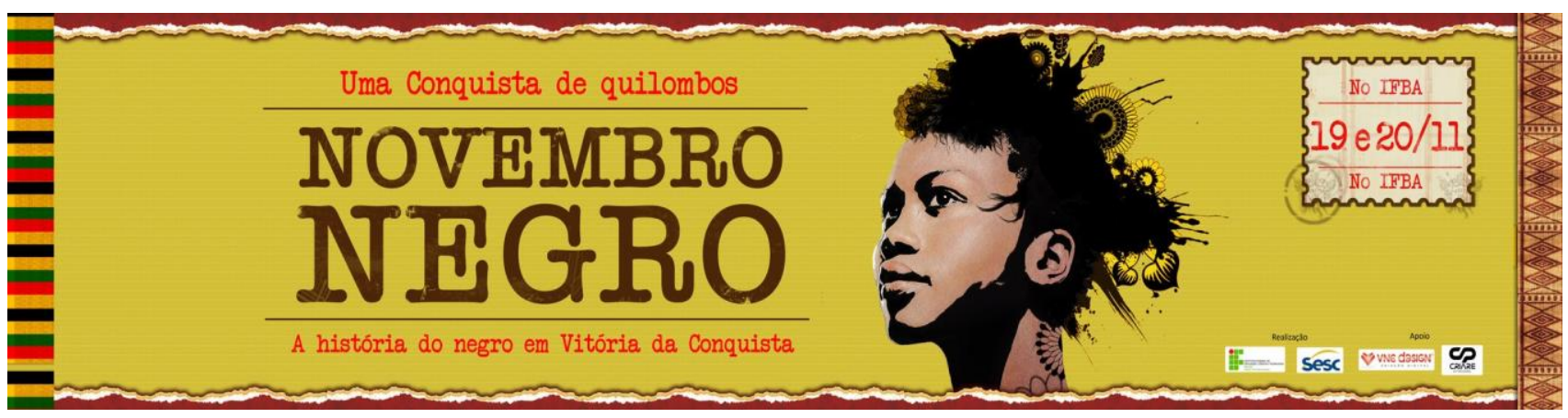

Figura 1: Marca oficial do Novembro Negro do IFBA, versão da 2a edição em 2012.

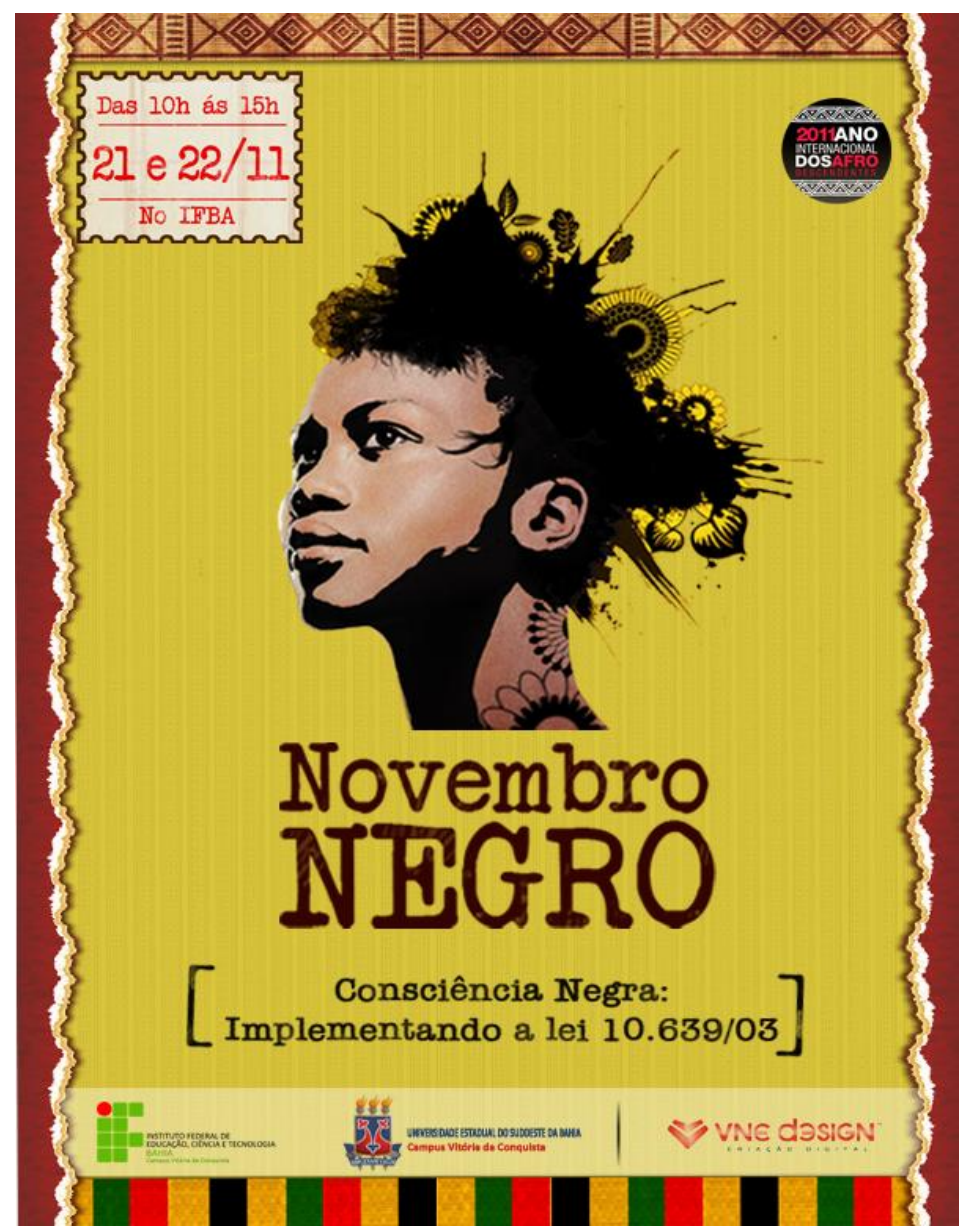

Figura 2: Marca oficial do Novembro Negro do IFBA, versão da 1ạ edição em 2011.

O município de Vitória da Conquista tem, segundo estimativas do IBGE (2010), uma população de aproximadamente 340 mil habitantes e é considerado a terceira maior cidade do estado da Bahia. Mas sua história muito explica a importância dos temas abordados pelo projeto, pois vincula-se diretamente à história regional, em especial quando rememorado o extermínio da população indígena (povos indígenas: Mongoyó, Pataxó e Ymboré). O fato do descobrimento da região sudoeste da Bahia, ter se dado por um preto forro, ou seja, um ex-escravo, vindo de Chaves em Portugal - João Gonçalves da Costa, provavelmente africano, segundo estudiosos da história regional, com chegada provável em 1720. Ter domínio do processo de constituição desse município baiano a partir de uma perspectiva que valorize as contribuições africanas e indígenas - 
inclusive suas contradições - e que também constitua uma prática curricular plural revela o papel questionador, crítico e consciente da educação, inclusive da educação profissional.

Diante de todo esse resgate e aprofundamento crítico e questionador das desigualdades, esses eventos trazem para a comunidade acadêmica não só a implantação de uma Lei, mas, sobretudo, um momento de reflexão, de provocação e de revisão sobre atos voluntários e involuntários acerca do racismo e das desigualdades históricas. São relevantes as discussões em torno da contribuição histórica que o negro trouxe na formação do Brasil. Também é destaque o fato do negro historicamente ter ficado nos espaços de subordinação e exploração, mesmo com a extinção da escravidão, já que não foram oferecidas condições dignas e igualitárias de se estabelecer socialmente.

\section{MATERIAIS E MÉTODOS}

O evento consiste anualmente em organização desde o primeiro mês letivo do ano, com previsão no calendário letivo oficial da Instituição como determina a Lei 10.639/03 com produções tanto docentes, quanto discentes. Desde produções audiovisuais, teatrais, musicais, fotográficas, apresentações de trabalhos desenvolvidos em sala de aula sob a coordenação de ciências humanas, até a realização de pesquisas no campo, todas sob diversos temas e temáticas que transversalizam o diálogo no combate ao racismo e internalizam a citada Lei no currículo e nas práticas de ensino-aprendizagem do Instituto.

Opta-se por uma semana de atividades com programação intensa que contempla todas as modalidades de ensino: ensino médio integrado, subsequente, Proeja e superior, conforme mostra a Figura 3 com o auditório geral lotado durante as atividades do projeto.

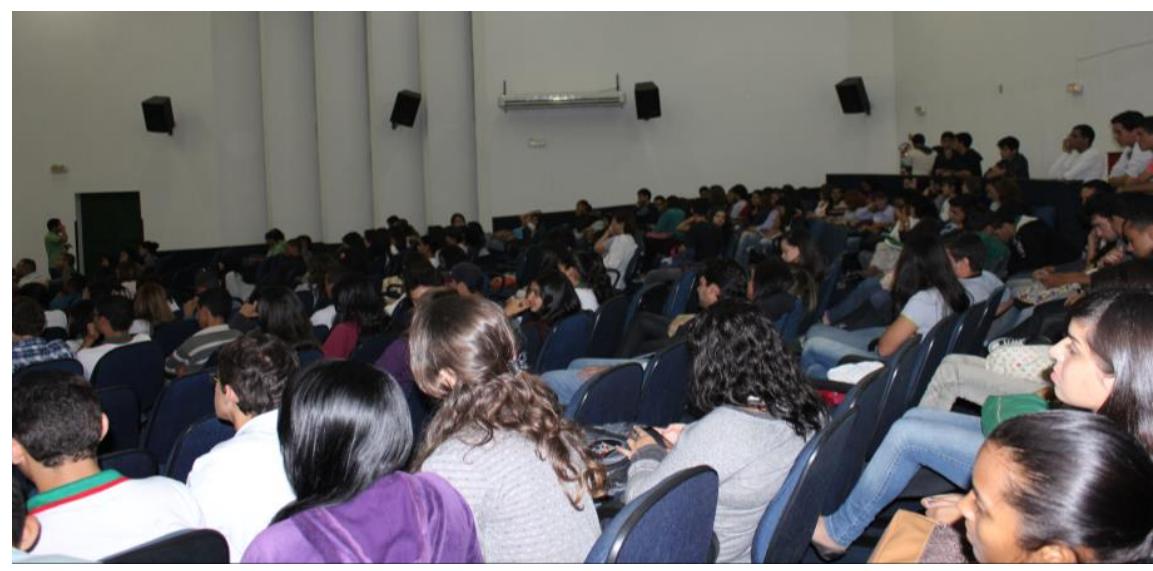

Figura 3: Vista parcial do Auditório Geral durante o II Novembro Negro do IFBA em 2012

Apresentam-se a seguir as experiências do projeto realizado em 2011, 2012 e 2013, por entender esses anos como os de consolidação de um evento que passou a ser uma prática cotidiana no processo de ensino-aprendizagem na dinâmica do instituto, integrando as diversas modalidades, séries e turmas.

Um dos debates mais fortes dar-se-á justamente em torno das Políticas de Ações Afirmativas, apresentadas como mecanismos legais de retratação a esse descabido abandono do povo negro na história do Brasil. Políticas públicas de Ações Afirmativas, como a criminalização do racismo, o estabelecimento de cotas, a aprovação do Estatuto da Igualdade Racial e a instituição da lei que torna obrigatório o ensino da História e Cultura afro-brasileira e africana nas instituições de 
ensino (Lei 10.639/03), são exemplos de reparos a favor da promoção do povo negro e superação da desigualdade social também provocada pelo racismo. Além disso, também é tema das Rodas de diálogos a questão da religiosidade de matriz africana, do gênero, do feminismo negro e da história do negro no sertão.

Buscando a valorização da cultura afro-brasileira, houve exibições de curtas produzidos pelos próprios discentes da instituição em 2011, disponibilizados em canal virtual do youtube, que trataram das "Expressões Culturais Afro-Brasileiras", tendo como símbolo maior a capoeira. Outra produção foi "Racismo, escravidão, luta e importância do negro no Brasil", discutindo um dos preconceitos mais perversos, o racismo, além do processo exploratório desumano que foi a escravidão, mas onde o negro, mesmo subordinado e negado de direitos, não abandonou suas raízes. Em parceria, foi produzido curta com a Associação Casa do Boneco, instituição que valoriza e desenvolve no município de Itacaré-BA, práticas de economia solidária, aliadas à cultura afrobrasileira. Houve ainda a exibição do curta "Racismo? Existe ou não existe?", provocando o público que o assistia a pensar nas pequenas ações que em suma manifestam o racismo internalizado. Por último, houve a exibição do curta "Personalidades Negras", mostrando a existência também de negros/as juízes, políticos, intelectuais, ministros, entre outros. Já em 2012, além de oficinas como a da Figura 4, foi dado importante destaque às comunidades quilombolas da região, ao todo vinte e sete (27) certificadas pela Fundação Cultural Palmares, e outras quinze (15) em processo de autodeclaração. Foram produzidos pelo projeto Novembro Negro quatro (4) documentários que registraram os diferentes olhares, as curiosas histórias de formação dessas comunidades e de seus patriarcas e matriarcas, as diferentes localidades, as dificuldades de permanência e reconhecimento do direito à terra e a manutenção da agricultura familiar nas seguintes produções: "Lagoa de Maria Clemência - A religiosidade de um povo"; "Boqueirão - A tradição de um povo"; "Lagoa de Melquíades e Amâncio" e "São Joaquim de Paulo - Uma História de Resistência", tendo sido esse último um finalista durante o Festival Internacional Porto 7, festival de cinema realizado em Portugal tendo outros 5 documentários finalistas e sendo o único brasileiro (IFBA, 2013). Em 2013, enfatizou-se a construção da identidade afro-indígena no sudoeste baiano, com palestras mais curtas, pois se privilegiou a apresentação dos trabalhos produzidos pelos discentes em sala de aula, alguns apresentados em manifestações artísticas, mostras pelos corredores da instituição, seguido também de minicursos: "Pau, pano e pão - Educação dos negros no período colonial"; "Conversando sobre preconceitos", "A questão racial no Brasil: do pós-abolição às cotas raciais"; "A visão atual das religiões de raízes de matrizes africanas"; "Acesso à água na comunidade quilombola Barrocas-Bahia" e das oficinas de trança, de teatro do Oprimido e de dança Afro.

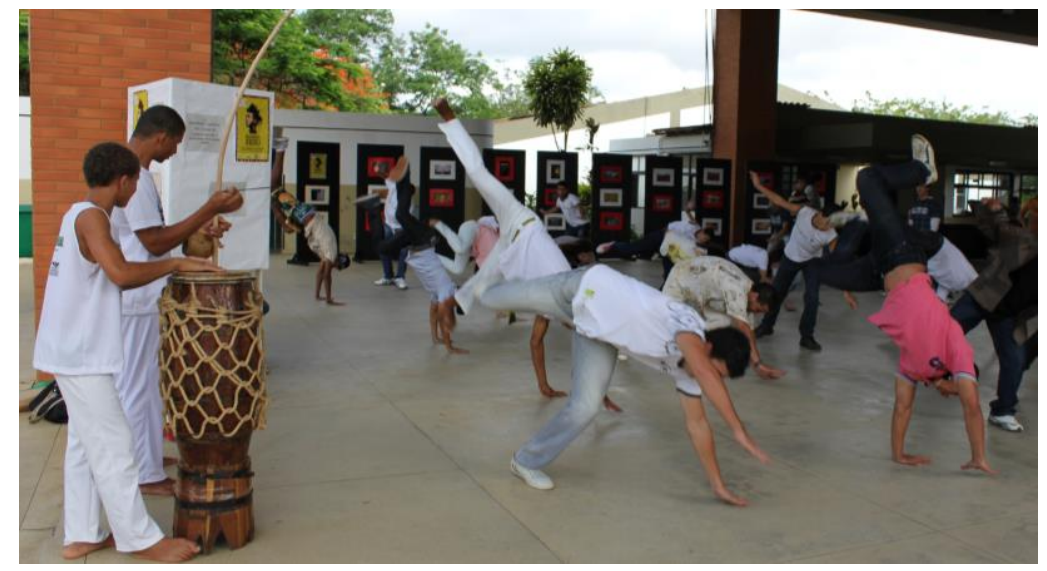

Figura 4: Oficina “Capoeirando" realizada em 2012 


\section{RESULTADOS E DISCUSSÃO}

No que diz respeito à percepção de racismo, preconceito e identidade foi realizada a pesquisa "Demandas de Cidadania" em 2011 e 2012 dentre os estudantes, importante meio de análise dessa realidade no IFBA, apresentando resultados que em si refletem o cotidiano da sociedade brasileira. A pesquisa foi realizada pelo método de amostragem, tendo o total de $162 \mathrm{e}$ 163 estudantes questionados na modalidade integrada de ensino, respectivamente nos anos de 2011 e 2012.

Dos questionados $46 \%$ se declararam do gênero masculino e $54 \%$ do gênero feminino no ano de 2011 , enquanto $59 \%$ se declararam do gênero masculino e $41 \%$ do gênero feminino no ano de 2012. Por sua vez, em relação à autodeclaração de cor/raça em 2011, foram 35\% de brancos, $13 \%$ de pretos, $3 \%$ de amarelos, $2 \%$ de indígenas e $47 \%$ de pardos. Já em 2012 , foram $38 \%$ de brancos, $19 \%$ de pretos, $3 \%$ de amarelos, $1 \%$ de indígenas e $39 \%$ de pardos. Segundo o Art. $2^{\circ}$, Parágrafo III do Estatuto da Igualdade Racial, "afro-brasileiros: [são] as pessoas que se classificam como tais ou como negros, pretos, pardos ou por definição análoga" (Lei 12.288, 2010, grifo nosso). Se somarmos os afro-brasileiros (negros e pardos) como o próprio Estatuto determina, tem-se uma média aproximada de $60 \%$ de afro-brasileiros autodeclarados na comunidade estudantil do IFBA.

Considerado um assunto polêmico, as ações afirmativas, em especial, as cotas, geram certo desconforto e descontentamento em uns e em outros apenas uma justa reparação de sequelas históricas. Citando novamente o Estatuto da Igualdade Racial, inclusive de autoria do único Senador brasileiro autodeclarado negro, Paulo Paim, o Art. $2^{\circ}$, Parágrafo $\mathrm{V}$, define "ações afirmativas: [são] as políticas públicas adotadas pelo Estado para a correção das desigualdades raciais e para a promoção da igualdade de oportunidades" (Lei 12.288, 2010, grifo nosso). Sabe-se que diversas instituições de ensino adotam como ações afirmativas as cotas raciais e/ou sociais, estabelecendo uma nota de corte para o ingresso, por exemplo, no ensino superior, mais recentemente normatizada pela Lei 12.711 (2012) que determina os coeficientes para estudantes cotistas nas Universidades e Institutos Federais, após as cotas raciais adotadas pela UnB terem ido a julgamento no Supremo Tribunal Federal (STF), sendo aprovadas por unanimidade (STF, 2012; Lei 12.711, 2012). O IFBA também a utiliza como ação afirmativa desde 2006 (Cefet-BA, 2006). Ao serem questionados sobre o uso de cotas para o ingresso no IFBA, $68 \%$ dos estudantes não utilizou, $23 \%$ usou cotas sociais, $7 \%$ raciais, $1 \%$ indígena e $1 \%$ cotas para portadores de necessidades especiais. Ainda sobre as cotas, $64 \%$ afirma ser a favor e $36 \%$ contra em 2011 , e $79 \%$ afirma ser a favor e $21 \%$ contra em 2012, demonstrando uma diferença de $15 \%$ entre os anos pesquisados na opinião expressa pelos estudantes, e, portanto, a revisão de conceitos sob orientação dos debates colocados em pauta no IFBA. Já em relação a qual modalidade de cotas é a favor, em 2011, 71\% afirma ser a favor das cotas sociais, $4 \%$ das raciais e $25 \%$ de ambas e em 2012 , $71 \%$ afirma ser a favor das cotas sociais, $17 \%$ das raciais, $11 \%$ para quilombolas e $24 \%$ a favor de todas.

A pesquisa também aponta que em 2011 , 76\% afirma existir preconceito no IFBA, e $24 \%$ afirma não existir e já em 2012, 35\% afirma existir preconceito no IFBA, e 65\% afirma não existir, considerando que em ambos os anos pesquisados $100 \%$ dos estudantes afirmou existir preconceito no Brasil. Em relação à existência de racismo, $41 \%$ afirma existir, e 59\% afirma não existir em 2011, considerando-se a inexistência de dados referentes ao ano de 2012. Mas ao serem questionados se são racistas, a resposta é curiosa, 100\% afirma não ser racista, mesmo sendo esses os mesmos que responderam à existência de racismo no IFBA. Outra curiosidade é que 
98,5\% dos questionados afirma que as expressões culturais promovidas pelo negro, tais como a dança, a capoeira, a culinária, as religiões de matriz africana são válidas e importantes para o Brasil, mas disso nasce o questionamento: se o negro é tão importante, porque ainda há racismo?

O Novembro Negro vem à tona não apenas como pontualidade do Mês da Consciência Negra, mas também como provocador na descoberta desta sociedade multicultural durante todo o ano. Desenvolver a consciência e uma educação antirracista torna-se fundamentalmente necessário para que haja igualdade e equivalência nos direitos sociais relativos às dinâmicas de gênero, orientação e identidade sexual, cor, raça, religião, origem social e regional e preferência político-ideológica.

Outro importante espaço para aproximação de estudiosos com estudantes, professores e convidados são as conferências de abertura e encerramento, que promovem diálogos ainda não socializados no ambiente do Instituto e importantes para difusão da educação antirracista proposta por este projeto. A exemplo da $1^{\circ}$ edição do Novembro Negro, que contou com a participação do Professor Dr. Itamar Pereira de Aguiar da UESB discutindo na abertura "O Sincretismo Religioso nos Candomblés do Sertão" e no encerramento a convidada da UNEB, Professora Ma. Marluce Gomes falando sobre os "Intelectuais Negros".

As apresentações culturais promovem um importante espaço na Instituição de participação dos estudantes, professores, técnico-administrativos e convidados que se manifestam sambando, com palmas ou apenas observando o Grupo Movimento Cultural Consciência Negra que demonstra a essência do samba e do maculelê e uma envolvente roda de samba com o Grupo as Nêgas do Beco, conforme a Figura 5, ambos parceiros do IFBA na consolidação de práticas que valorizem e destaquem como protagonista o antes historicamente excluído da sociedade, pois "O racismo é a chave para se entender e superar a reprodução da pobreza e das desigualdades sociais no Brasil" como afirma Mário Theodoro.

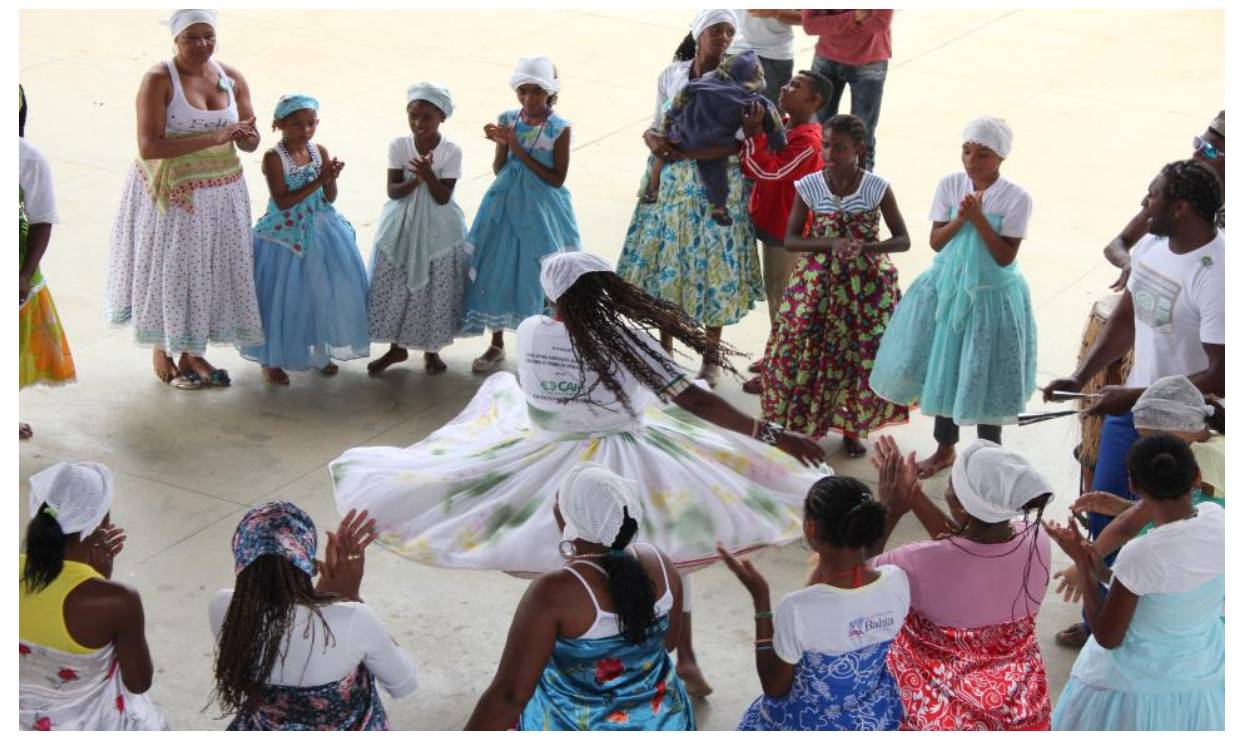

Figura 1: Apresentação cultural do Grupo de Samba Nêgas do Beco em 2012

É importante destacar que o projeto foi idealizado pelo doutorando em História pela UFBA e professor do IFBA campus Camaçari Alex Ivo, quando ainda era lotado no campus Vitória Conquista, no sentido de disseminar uma consciência e uma educação antirracista. Prof. Alex, também palestrante do evento, afirmou para reportagem da Coordenação de Comunicação do campus que: 


\begin{abstract}
"Nós, negros, temos um dever e um compromisso com todos os nossos que não tiveram a mesma sorte que nós, de termos acesso à educação, acesso aos bancos das universidades. Então nós temos obrigação de trazer esse tema, fazer com que ele seja pensado e que isso transforme e dê lugar para que mais pessoas ocupem esses espaços que são espaços de poder" (IFBA, 2011)
\end{abstract}

\title{
4 PARA NÃO CONCLUIR
}

A insistência em discutir e internalizar a Lei 10.639/03 nos currículos e nas práticas de ensino-aprendizagem das instituições de ensino, em seu caráter social de reflexão e interpretação da realidade enquanto cultural e também desigual, exige dos negros e não negros a revisão de conceitos, práticas, métodos, discursos, olhares, e tudo aquilo que expresse uma postura não condizente com o respeito à diversidade, expressão essa maior do homem.

Ressalta-se ainda que o Novembro Negro é um ponto de partida, e não uma atividade pontual. O desejo é que se construa uma escola e uma sociedade com valores de igualdade e respeito às multiculturalidades: uma sociedade cuja maioria da população de pretos e pardos constitua também maioria nas esferas de poder e nos espaços de decisão, efetivamente.

Vale lembrar que o evento conta com uma equipe de docentes e discentes da área de ciências humanas que organizam os trabalhos.

Acredita-se que a provocação foi lançada e retornará com bons resultados, inclusive quando considerado que a consolidação do Novembro Negro do IFBA como prática está incorporada ao cotidiano de ensino-aprendizagem do ensino integrado ao ensino superior. Em todas as modalidades de ensino dessa instituição de educação federal a temática em que atravessa uma Educação Antirracista e consolida práticas e currículos humanizadores, tem tido destaque e reverbera como uma proposta interdisciplinar de pensar a história e cultura do povo negro como uma importante e potente intervenção no cotidiano escolar.

Demonstrando diversas possibilidades acerca da implementação de uma lei historicamente reivindicada pelos movimentos sociais negros, em especial na dinâmica própria da formação técnico-profissional dos institutos federais, ampliando, e quiçá servindo como modelo, como prática, como inspiração e exemplo de sucesso no cumprimento para além da referida exigência legal, mas também como um aceno para multi olhares acerca de uma abordagem tão necessária, que é a educação antirracista dentro da escola. Avizinha-se com práticas como essas, de que um horizonte de respeito e dignidade se apresenta a todos os homens e mulheres, negros, negras e não negros que têm seu legado na história e na cultura desse país. 


\section{REFERÊNCIAS}

Lei n. 10.639, de 9 de janeiro de 2003. Altera a Lei no 9.394, de 20 de dezembro de 1996, que estabelece as diretrizes e bases da educação nacional, para incluir no currículo oficial da rede de ensino a obrigatoriedade da temática "História e Cultura Afro-Brasileira e Africana", e dá outras providências. Brasília. http://www.planalto.gov.br/ccivil 03/leis/2003/L10.639.htm

Lei n. 11.645, de 10 de março de 2008. Altera a Lei no 9.394, de 20 de dezembro de 1996, modificada pela Lei no 10.639, de 9 de janeiro de 2003, que estabelece as diretrizes e bases da educação nacional, para incluir no currículo oficial da rede de ensino a obrigatoriedade da temática História e Cultura Afro-Brasileira e Indígena e dá outras providências. Brasília. Recuperado de http://www.planalto.gov.br/ccivil 03/ ato2007-2010/2008/lei/l11645.htm

Lei n. 11.892, de 29 de dezembro de 2008. Institui a Rede Federal de Educação Profissional, Científica e Tecnológica, cria os Institutos Federais de Educação, Ciência e Tecnologia, e dá outras providências. Brasília. Recuperado de http://www.planalto.gov.br/ccivil 03/ ato20072010/2008/lei/l11892.htm

Lei n. 12.288, de 20 de julho de 2010. Institui o Estatuto da Igualdade Racial; altera as Leis $\mathrm{n}^{\text {o }}$ 7.716, de 5 de janeiro de 1989, 9.029, de 13 de abril de 1995, 7.347, de 24 de julho de 1985, e 10.778, de 24 de novembro de 2003. Brasília. Recuperado de http://www.planalto.gov.br/ccivil 03/ ato2007-2010/2010/lei/l12288.htm

Lei n. 12.711, de 29 de agosto de 2012. Dispõe sobre o ingresso nas universidades federais e nas instituições federais de ensino técnico de nível médio e dá outras providências. Brasília. Recuperado de http://www.planalto.gov.br/ccivil 03/ ato2011-2014/2012/Lei/L12711.htm

Portaria Interministerial MEC/MJ/SEPPIR n. 605, de 20 de maio de 2008. Institui Grupo de Trabalho Interinstitucional com a finalidade de elaborar metas e estratégias nacionais que visam subsidiar a construção de indicadores para implementação da Lei 10.639/2003. Brasília. Recuperado de http://portal.mec.gov.br/arquivos/pdf/portaria mec.pdfCNE/CP

Resolução n. 1, de 17 de junho de 2004. Institui Diretrizes Curriculares Nacionais para a Educação das Relações Étnico-Raciais e para o Ensino de História e Cultura Afro-brasileira e Africana. Recuperado de http://portal.mec.gov.br/cne/arquivos/pdf/res012004.pdf

Cefet-BA. (2006). Resolução no 10, de 10 de junho de 2006. Estabelece reservas de vagas para afrodescendentes, índios e índios descendentes, nos cursos do CEFET-BA realizados através de Vestibular/Seleção. Recuperado de: http://www.ifba.edu.br/informativo/resolucoes/RE 102006 Sobre COTAS.pdf

Ferraz, L. A.. (2011). Lei $n^{\circ}$ 10.639/03: uma nova possibilidade de reconhecimento da história e cultura afro-brasileira e africana (Trabalho de conclusão de curso). Universidade Estadual de Londrina - UEL, Londrina, PR, Brasil. Recuperado de http://www.uel.br/ceca/pedagogia/pages/arquivos/LUCIANE\%20APARECIDA\%20FERRAZ.pdf

Gomes, N. L.. (2010). Educação, relações étnico-raciais e a Lei 10.639/03. In: Brandão, A. P. (org). Modos de Fazer: caderno de atividades, saberes e fazeres. - Rio de Janeiro: Fundação Roberto Marinho, v. 4. Recuperado de http://www.acordacultura.org.br/sites/default/files/kit/MODOSDEFAZER-WEBCORRIGIDA.pdf

IBGE. (2010). Bahia - Vitória da Conquista. Recuperado de http://cod.ibge.gov.br/1SX

IFBA. (2011). Novembro Negro 2011. Recuperado de


http://www.conquista.ifba.edu.br/index.php/component/content/article/86-

ifba/noticias/493-novembro-negro

IFBA. (2013). Documentário produzido no IFBA Conquista concorre no Festival Porto 7. 2013. Recuperado de http://www.conquista.ifba.edu.br/index.php/mais-noticias/832documentario-produzido-no-ifba-conquista-concorre-no-festival-porto-7

Macedo, Aldenora Conceição de. (2014). Gestão escolar e educação antirracista: a implementação da Lei 10.639/2003 na perspectiva da educação como direito. Monografia (Especialização em Gestão Escolar). Universidade de Brasília - UnB, Brasília, Distrito Federal, Brasil.

Rocha, L. F. R.. (2015). A Implementação da Lei 10.639/2003 na Rede Federal de Educação Profissional, Científica e Tecnológica. Dissertação (Mestrado em Educação). Universidade Federal de Ouro Preto UFOP, Ouro Preto, MG, Brasil. Recuperado http://www.repositorio.ufop.br/handle/123456789/5695

STF. (2012). Íntegra do voto do ministro Lewandowski na ADPF sobre cotas. Recuperado de http://www.stf.jus.br/portal/cms/verNoticiaDetalhe.asp?idConteudo=205890 